Pesq. Vet. Bras. 37(9):984-990, setembro 2017

DOI: $10.1590 / \mathrm{S} 0100-736 \mathrm{X} 2017000900014$

\title{
Doença do corpúsculo de inclusão e espondilite por Salmonella sp. em uma Boa constrictor constrictor ${ }^{1}$
}

\author{
Isabela Hardt ${ }^{2 *}$, Maylla G. Gava ${ }^{2}$, Jeanne S. Paz ${ }^{3}$, Eduardo L.F. Silva ${ }^{4}$, Tayse D. Souza ${ }^{2}$ \\ Flavia F. Jabour ${ }^{2}$, Flaviana L.G. Leite ${ }^{3}$ e Mayra C. Flecher ${ }^{2}$
}

\begin{abstract}
ABSTRAT.- Hardt I., Gava M.G., Paz J.S., Silva E.L.F., Souza T.D., Jabour F.F., Leite F.L.G. \& Flecher M.C. 2017. [Inclusion body disease and spondilitis by Salmonella sp. in a Boa constrictor constrictor.] Doença do corpúsculo de inclusão e espondilite por Salmonella sp. em uma Boa constrictor constrictor. Pesquisa Veterinária Brasileira 37(9):984-990. Setor de Patologia Veterinária, Universidade de Vila Velha, Complexo Nossa Senhora da Penha (biopráticas), Rua Viana s/n, Boa Vista, Vila Velha, ES 29102770, Brazil. E-mail: isabelahardt@yahoo.com.br

Inclusion Body Disease (IBD) is a disorder characterized by intracytoplasmic corpuscles in different tissues, mainly in the CNS, wich is responsible for the major neurological signs attributable to this disease. It affects Boas and Phytons in captivity and have been a global concern due to the high morbidity and mortality. The diagnosis is made by visualization of corpuscles caused by a modified Arenaviruses. Salmonella sp. belongs to microflora of cold and warm-blooded animals; it is an opportunistic pathogen that can causes gastrointestinal or septic disorders. In reptiles, Salmonella sp. is the bacteria most frequently quotes in spondylitis and osteomyelitis. This article describes a boa constrictor (Boa constrictor constrictor) that had restriction of movement and multiple granulomas in the dorsal vertebrae, the shadowgraph showed up fractured regions. After months of treatment without clinical improvement and the emergence of new injuries, the animal started to get prostrate, anorexic, cachectic and developed opisthotonos. It was opted for euthanasia. At necropsy it was found in multiple spots swelling of the dorsal vertebrae that ranging from mild to moderate. At the cutting vertebrae it was visible deformed and showed focal caseous content near the spinal cord, this was collected for microbiology where it was identified Salmonella sp. At microscopic evaluation the vertebrae had one to multifocal moderate inflammatory infiltrate of macrophages and heterophils. Some areas had lots of granulomas with central calcification and numerous giant cells. Other vertebras showed areas of osteomalácea and fibrosis. Rare focus had vertebral body fracture and spinal cord compression with mild infiltration entering the spinal cord canal. In the lung, especially in the bronchial epithelium, sometimes even within lymphocytes in bronchial-associated lymphoid tissue, in the intestine, liver, gall bladder, kidney and brain were found various structures of eosinophilic intracytoplasmic rounded ranging between 1 and 10 micrometers. These structures accompanied or not mononuclear inflammation. These findings are consistent with IBD and spondylitis due to salmonellosis. The IBD is a common disease in captive snakes, of world importance, is probably underdiagnosed in Brazil. This disease causes immunosuppression favoring the development of other affections, and is typically associated with other diseases such as spondylitis found in the case.
\end{abstract}

INDEX TERMS: Inclusion body disease, spondylitis, Salmonella sp., Boa constrictor constrictor, arenavirus, snakes, virus, salmonellosis.

\footnotetext{
${ }^{1}$ Recebido em 20 de março de 2016.

Aceito para publicação em 24 de novembro de 2016.

${ }^{2}$ Setor de Patologia Veterinária, Universidade de Vila Velha (UVV), Complexo Nossa Senhora da Penha (biopráticas), Rua Viana s/n - Boa Vista, Vila Velha, ES 29102770, Brasil. *Autor para correspondência: isabelahardt@yahoo.com.br
}

\footnotetext{
${ }^{3}$ Hospital Veterinário Ricardo Alexandre Hippler, UVV, Complexo Nossa Senhora da Penha (biopráticas), Rua Viana s/n, Boa Vista, Vila Velha, ES 9102770, Brasil.

${ }^{4}$ Veterinário autônomo, Avenida dos Ipês, 99, Morada do Sol, Vila Velha, ES 29129-721, Brasil.
} 
RESUMO.- Doença do corpúsculo de inclusão (IBD) é uma enfermidade caracterizada por corpúsculos intracitoplasmáticos em diversos tecidos, principalmente no sistema nervoso central, responsável pelos principais sinais clínicos atribuídos à doença que acomete Boas e Phytons de cativeiro; essa enfermidade tem sido uma preocupação mundial devido à alta morbidade e mortalidade. 0 diagnóstico é feito pela visualização dos corpúsculos causados por um Arenavírus modificado. Salmonella sp. pertence à microflora de animais de sangue frio e quente, e é um patógeno oportunista que pode causar quadros gastrointestinais ou septicêmicos. Em répteis a Salmonella sp. é a bactéria com maior frequência de citações em espondilites e osteomielites. Relata-se um caso de uma jiboia (Boa constrictor constrictor) que apresentava restrição de movimento e múltiplos granulomas dorsais nas vértebras; à radiografia evidenciaram-se regiões fraturadas. Após meses de tratamentos sem melhora clínica e o aparecimento de novas lesões o animal ficou prostrado, anoréxico, caquético e desenvolveu opistótono; optou-se pela eutanásia. À necropsia verificaram-se, nas vértebras, múltiplos focos dorsais com aumento de volume que variava de $1,7 \mathrm{~cm}$ à $3,8 \mathrm{~cm}$. Ao corte as vértebras eram deformadas e exibiam conteúdo caseoso focal próximo ao canal medular, este foi coletado para microbiologia onde se identificou Salmonella sp. À microscopia as vértebras tinham um infiltrado inflamatório multifocal moderado de macrófagos e heterofilos. Algumas áreas possuíam grande quantidade de granulomas com calcificação central e inúmeras células gigantes; outros mostravam áreas de osteomalácia e fibrose. Em raros focos havia fratura do corpo vertebral e compressão da medula espinhal com leve infiltrado inflamatório invadindo o canal medular. No pulmão, principalmente no epitélio brônquico, por vezes até dentro de linfócitos do tecido linfoide bronco-associado, no intestino, fígado, vesícula biliar, nos rins e no encéfalo foram encontradas diversas estruturas eosinofílicas intracitoplasmáticas arredondadas que variavam de 1 a $10 \mu \mathrm{m}$. Essas estruturas acompanhavam ou não inflamações mononucleares. Os achados são compatíveis com IBD e espondilite por salmonelose. A IBD é uma enfermidade frequente em serpentes de cativeiro, de importância mundial, que provavelmente é subdiagnosticada no Brasil. Essa doença causa imunossupressão que favorece ao desenvolvimento de outras enfermidades, e é tipicamente associada a outras doenças como a espondilite encontrada no caso.

TERMOS DE INDEXAÇÃO: Doença do corpúsculo de inclusão, espondilite, Salmonella sp., Boa constrictor constrictor, arenavírus, serpentes, vírus, salmonelose.

\section{INTRODUÇÃo}

Doença do corpúsculo de inclusão (Inclusion body disease - IBD) é uma enfermidade que afeta serpentes, principalmente Pythonidae e Boidae (Schumacher et al. 1994, Schumacher 2006, Chang \& Jacobson 2010, Stenglein et al. 2012, Hetzel et al. 2013, Chang et al. 2013, Turchetti et al. 2013). Foi descrita pela primeira vez há quatro décadas e têm sido uma preocupação mundial devido à alta morbidade e mortalidade (Chang \& Jacobson 2010, Stenglein et al. 2012, Hetzel et al. 2013, Chang et al. 2013). Entretanto, até o momento, só há um relato de caso de IBD no Brasil (Turchetti et al. 2013).

A doença se caracteriza por corpúsculos intracitoplasmáticos em diversos tecidos (Schumacher et al. 1994, Schumacher 2006, Chang \& Jacobson 2010, Stenglein et al. 2012, Chang et al. 2013, Hetzel et al. 2013, Turchetti et al. 2013) e os sinais clínicos são consequência das inclusões no sistema nervoso central, levando a opistótono, desequilíbrio, paralisia flácida e inabilidade de voltar à posição quando colocados em decúbito dorsal (Chang \& Jacobson 2010, Stenglein et al. 2012), anisocoria e tremores da cabeça (Hetzel et al. 2013). Além dos sinais neurológicos, sinais clínicos inespecíficos como anorexia, apatia (Hetzel et al. 2013, Turchetti et al. 2013) e regurgitação já foram associados à enfermidade (Schumacher et al. 1994, Chang \& Jacobson 2010, Stenglein et al. 2012, Hetzel et al. 2013, Turchetti et al. 2013).

Diversos aspectos da IBD ainda não foram suficientemente elucidados, como epidemiologia e transmissão. Recentemente, identificou-se que um Arenavirus modificado é o responsável pela doença (Stenglein et al. 2012, Bodewes et al. 2013, Hetzel et al. 2013). Acredita-se que a transmissão ocorra por contato direto entre animais infectados e por via transovariana. Ainda supõe-se que o piolho Ophionyssus natricis facilita a disseminação da doença entre populações de serpentes (Schumacher 2006, Chang \& Jacobson 2010, Stenglein et al. 2012).

Achados clínicos e patológicos frequentemente relacionados à enfermidade incluem estomatite, pneumonia, desordens linfoproliferativas e neoplasias de células redondas (Schumacher et al. 1994, Chang \& Jacobson 2010, Stenglein et al. 2012, Hetzel et al. 2013, Turchetti et al. 2013). 0 diagnóstico microscópico é realizado pela visualização de corpúsculos intracitoplasmáticas que variam de eosinofílicos a anfofílicos à coloração hematoxilina-eosina em diversos órgãos (Schumacher et al. 1994 Schumacher 2006, Chang \& Jacobson 2010, Stenglein et al. 2012, Hetzel et al. 2013, Chang et al. 2013, Turchetti et al. 2013). Ao microscópio eletrônico, as degenerações hialinas aparecem como estruturas sólidas eletrodensas, de 0,1 a 40 micrometros, em diversos tipos celulares. As de menor tamanho são caracterizados como um material granular; por vezes há subunidades menores próximas, envoltas por grupos de ribossomos (Chang \& Jacobson 2010, Hetzel et al. 2013, Turchetti et al. 2013).

Nos animais em cativeiro ou domesticados, o desenvolvimento de infecções é facilitado pela imunossupressão devido à frequente exposição a novos patógenos num ambiente hostil, e o contínuo estresse do manejo (Schumacher 2006). Em répteis, septicemias bacterianas costumam levar a infecções ósseas (Jacobson 2007a), e Salmonella sp., componente de sua microbiota, tem potencial para se tornar um patógeno quando há alteração da flora (Hirsh 1990a, 1990b, Quinn et al. 2000, Jacobson 2007a, Bastos 2012), geralmente causadas por estresse, restrição ou mudança abrupta alimentar, redução do peristaltismo ou antibioticoterapia prolongada (Quinn et al. 2000, Jacobson 2007a), além de fatores relacionados à interação entre o hospedeiro 
e a salmonela como resistência do hospedeiro, dose infectante, virulência, disponibilidade de receptores celulares para a bactéria e exposição prévia (Hirsh 1990a, Gelberg 2013). Entre os sorogrupos de Salmonella spp., o IIIa é o mais importante para répteis, sendo que os relatos incluem com maior frequência a Arizonae e Arizonae hinshawii (Jacobson 2007a, Bastos 2012). Em répteis, essas bactérias além de associadas aos quadros de osteomielite, já foram relatadas causando infecções no trato urinário (Jacobson 2007a), e em serpentes foram descritas causando coelomite, ooforite, salpingite (Bastos 2012), artrite, estomatite, gastrite necrotizante, enterite fibrinonecrótica, abcessos multifocais na serosa gastrointestinal, com envolvimento da vesícula biliar, baço e pulmão, abcessos intraoculares (Jacobson 2007a), abcessos hepáticos (Bastos 2012), epicardite e miocardite granulomatosa, traqueíte necrotizante, pneumonias, lesões no fígado, baço, vasos sanguíneos (Jacobson 2007a) e septicemia (Jacobson 2007a, Bastos 2012).

A evolução da infecção pode levar à morte em todas as espécies susceptíveis à salmonelose. Alguns animais têm a infecção auto-limitante, o que os torna reservatórios, e eliminam a bactéria nas fezes, principalmente em situações pós-estresse, e se transformam em fonte de infecção para outros animais e pessoas (Gelberg 2013). As cepas isoladas de Salmonella spp. proveniente dos répteis são consideradas mais patogênicas para o ser humano do que as de aves e mamíferos sendo de grande importância para tratadores de cativeiro de répteis, embora seja negligenciada (Jacobson 2007a).

Baseado nos achados clínicos e anatomopatológicos relata-se um caso de doença do corpúsculo de inclusão e espondilite por salmonelose em uma Boa constrictor constrictor (jiboia). Esse diagnóstico ressalta a necessidade de maiores estudos em animais silvestres e chama atenção para que novos relatos de IBD possam contribuir para melhor compreensão da afecção e epidemiologia no Brasil.

\section{MATERIAL E MÉTODOS}

Uma Boa constrictor constrictor (jiboia) foi adquirida pelo proprietário em março de 2012 com dois meses de idade. Em maio de 2013 apresentou áreas multifocais de aumento de volume por toda a coluna vertebral, que não coincidiu com nenhum acontecimento notório como mudança alimentar ou de manejo. A princípio mostrava discreta restrição de movimento que não impediam seus hábitos naturais. Foram realizadas radiografia da coluna vertebral e hemocultura.

0 tratamento consistiu em enrofloxacina intramuscular durante 28 dias e meloxicam intramuscular durante 6 dias: animal apresentou uma melhora discreta no quadro clínico, por isso utilizou-se como terapia auxiliar Ozonioterapia, que foi realizada semanalmente durante seis meses. 0 paciente apresentou uma melhora significativa e o quadro permaneceu estável, até que em março de 2014, novas áreas multifocais surgiram na coluna, a restrição dos movimentos agravou-se severamente, e a serpente começou a ter convulsões, opistotóno e caquexia. Optou-se pela eutanásia do animal, que foi realizado com tiletamina- zolazepam intramuscular e aprofundado com Isoflurano inalatório, após a verificação dos estágios e planos anestésicos, foi injetado Cloreto de potássio IC (intra-cardíaco).
Posteriormente o animal foi encaminhado para o Setor de Patologia animal do hospital Professor Ricardo Alexandre Hippler para avaliação necroscópica.

Após o procedimento, vértebras e as demais vísceras foram coletadas e acondicionadas em formol a 10\% tamponado. Após fixação, os ossos foram descalcificados em solução de ácido nítrico à $5 \%$, em seguida processados pela técnica de rotina para histopatologia.

O fígado, o coágulo cardíaco e o conteúdo vertebral foram coletados assepticamente e enviados ao setor de microbiologia veterinária para cultura bacteriana. Estas amostras foram inoculadas em caldo BHI (Brain heart infusion), ágar sangue, ágar MacConkey e ágar Salmonella-Shiguela (SS). Após 24 horas de cultivo em estufa bacteriológica a $37^{\circ} \mathrm{C}$ C, as colônias foram submetidas a um esfregaço com a coloração de Gram, ao teste de oxidase e ao sistema miniaturizado de identificação Bactray ${ }^{\circledR}$ (I e II) segundo as normas do fabricante.

\section{RESULTADOS}

0 resultado dos exames realizados frente à primeira quei$\mathrm{xa}$, ainda in vivo, foi na radiografia uma osteomielite multifocal nas vértebras caudais (Fig.1A-C) e na hemocultura isolou-se Salmonella sp.

À necropsia foi verificada caquexia acentuada e havia diversas áreas dorsais com aumento de volume, de $0,3 \mathrm{~cm}$ à $1,1 \mathrm{~cm}$ de consistência pétrea a firme. Ao exame da cavidade celomática, verificou-se que as vértebras estavam deformadas com aumento de volume que variava de $1,7 \mathrm{~cm}$ à $3,8 \mathrm{~cm}$ nos maiores eixos (Fig.2A), algumas exibiam ao corte, um material caseoso focal próximo ao canal medular (Fig.2B). À avaliação da cavidade celomática verificou-se que o aumento de volume era disseminado por toda a coluna vertebral (Fig.1D) e havia discreta quantidade de vasos hiperêmicos adjacentes às lesões (Fig.2C). Também foram observadas áreas amarronzadas multifocais na membrana celomática, áreas brancacentas aleatórias no fígado e um foco de hiperemia periodontal.

Ao exame microscópico, todas as vértebras coletadas para histopatologia tinham um infiltrado inflamatório multifocal composto por macrófagos e heterófilos, que variavam de moderados a abundantes. Geralmente estavam associadas a múltiplas áreas de necrose margeadas por células gigantes, macrófagos epitelioides e infiltrado linfohistiocítico; alguns exibiam calcificação central (Fig.3A). Ocasionalmente havia extensas áreas de necrose óssea com moderada fibrose entremeada, caracterizando uma espondilite granulomatosa multifocal acentuada crônica, ou grandes áreas de neoformação óssea e matriz não calcificada (Fig.3B). Em dois fragmentos foram notados ampla área de necrose e fratura do corpo vertebral, com invasão do tecido fragmentado para o forame medular e compressão da medula espinhal (Fig.3C e 3D). 0 tecido nervoso acometido encontrava-se achatado e alongado, com aumento da afinidade tintorial, e uma região bem delimitada necrótica (Fig.3D). Raramente foi observado um infiltrado linfohistiocitário leve com discreta quantidade de heterófilos e escasso material amorfo eosinofílico fibrilar invadindo a medula espinhal. No estroma ósseo adjacente à fratura das vértebras encontrou-se hemorragia e necrose eventuais.

Outros achados microscópicos foram coelomite he- 

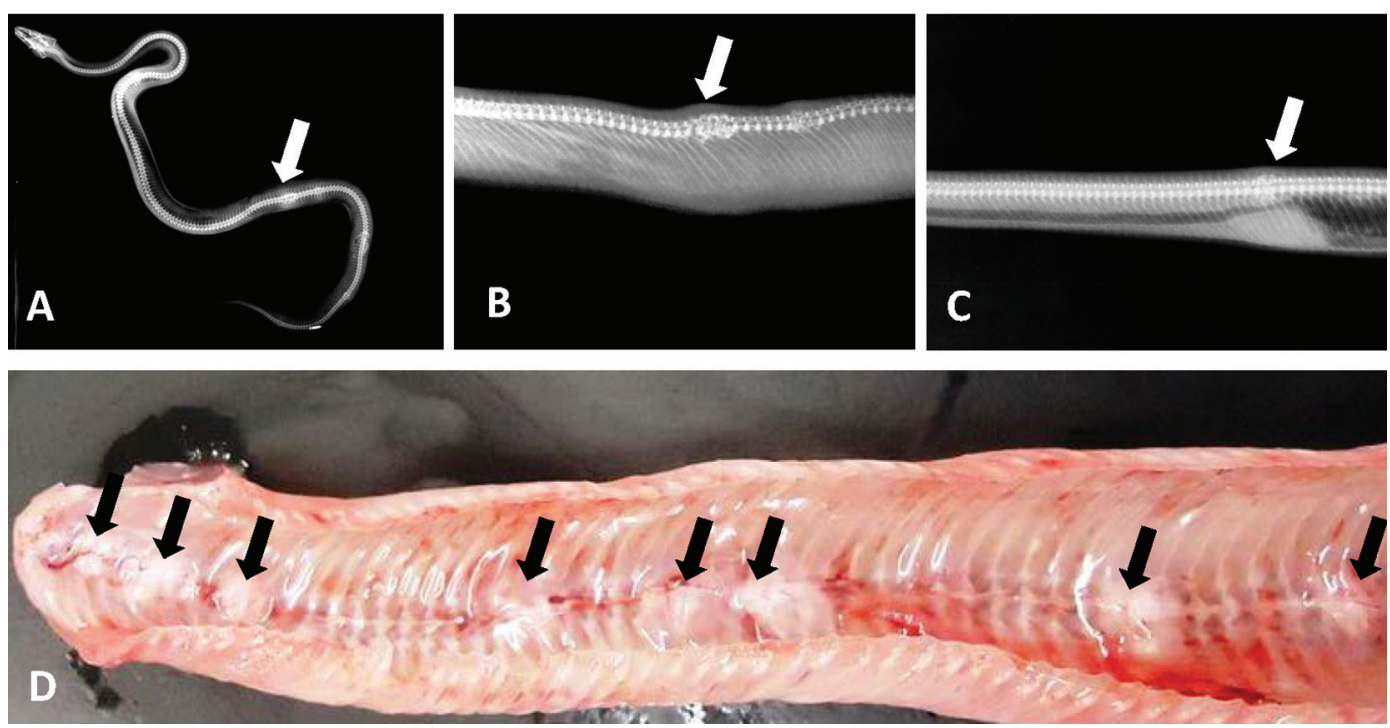

Fig.1. (A) Imagem radiográfica do corpo de Boa constrictor constrictor em decúbito caudo-dorsal, onde se evidenciam três áreas radiopacas, de diferentes tamanhos, no terço final das vértebras. (B,C) Imagens radiográficas dos focos de osteomielite ao longo da coluna vertebral. (D) Aspecto macroscópico dos focos de osteomielite ao longo da coluna vertebral, após a retirada dos órgãos à necropsia (da esquerda para a direita a disposição é crânio-caudal). 0 intervalo entre A, B e C para D foi de aproximadamente um ano.
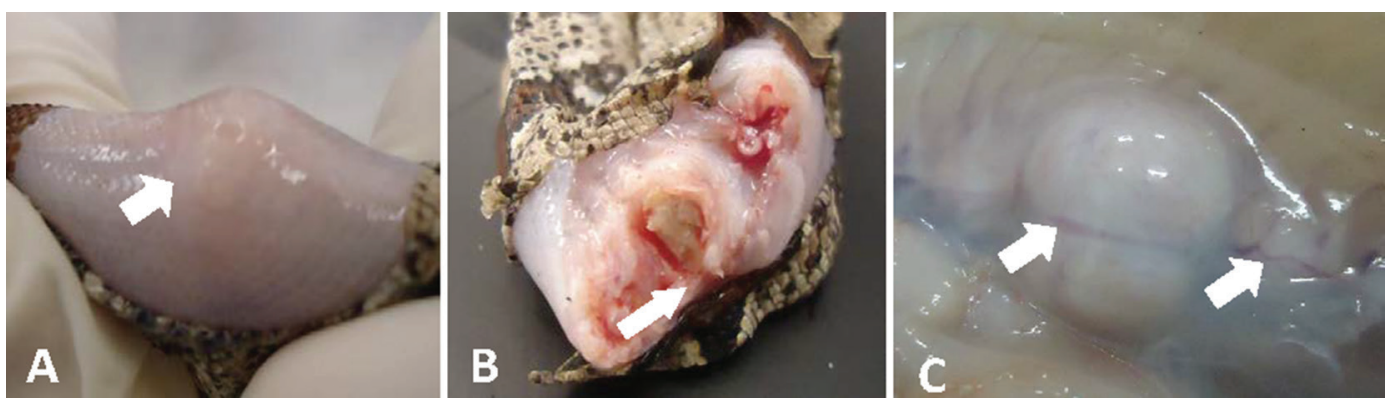

Fig.2. Lesão com aumento de volume e exsudato caseoso, adjacente à medula de uma Boa constrictor constrictor. (A) Vista dorsal da lesão, evidenciada por elevação do tecido subcutâneo e musculatura (seta). (B) Lesão ao corte exsudava material caseoso amarelado (seta). (C) Vista ventral da lesão.

morrágica difusa acentuada, pneumonia intersticial leve, hepatite histiocítica difusa discreta, colite multifocal a coalescente linfohistioplasmocitária discreta com raros heterófilos, nefrite intersticial histiocítica discreta.

Foram encontrados nas células do epitélio pulmonar (Fig.4A), da vesícula biliar (Fig.4B), do intestino (Fig.4C), do pâncreas exócrino (Fig.4D), nos hepatócitos, nas células tubulares renais (Fig.4E), em neurônios e células da glia (Fig.4F), corpúsculos eosinofílicos intracitoplasmáticos bem delimitados, medindo entre 1 e $10 \mathrm{~m} \mu$, disseminados em quantidade variada em cada tecido, em maior número no encéfalo e pâncreas.

Foram isoladas das vértebras colônias típicas de Salmonella sp. no agar SS; os testes bioquímicos confirmaram o gênero da bactéria e não houve crescimento bacteriano a partir dos inóculos dos demais tecidos.

A conclusão anatomopatológica foi compatível com IBD, devido às inclusões hialinas de diversos tecidos, e com uma espondilite granulomatosa multifocal acentuada crônico ativa, com fratura do corpo vertebral e consequente compressão da medula espinhal de natureza bacteriana (salmonelose) e consequente quadro septicêmico.

\section{DISCUSSÃO}

Os achados histopatológicos de inclusões eosinofílicas arredondadas intracitoplasmáticas são similares aos descritos na literatura nos casos de IBD (Schumacher et al. 1994, Schumacher 2006, Chang \& Jacobson 2010, Stenglein et al. 2012, Hetzel et al. 2013, Chang et al. 2013, Turchetti et al. 2013); a localização típica dos corpúsculos observados em jiboias também foi uma achado similar. Nessas serpentes, os corpúsculos são comumente encontrados nos neurônios, células da glia, nas células epiteliais do esôfago (adjacentes às tonsilas), trato gastrointestinal e respiratório, células tubulares renais, hepatócitos e células dos ácinos pancreáticos. As inclusões podem ser vistas também em eritrócitos, linfócitos e heterófilos (Chang \& Jacobson 2010), e inflamação histiocítica pode estar associada ou ausente (Chang \& Jacobson 2010, Turchetti et al. 2013). Alguns achados considerados menos frequentes foram encontrados, como corpúsculos nos linfócitos do tecido linfoide bronco-associado (Chang \& Jacobson 2010).

Como resultado das inclusões nas células sanguíneas, leucócitos e células mielopoéticas, há imunossupressão, o que predispõe às infecções bacterianas, fúngicas e protozo- 


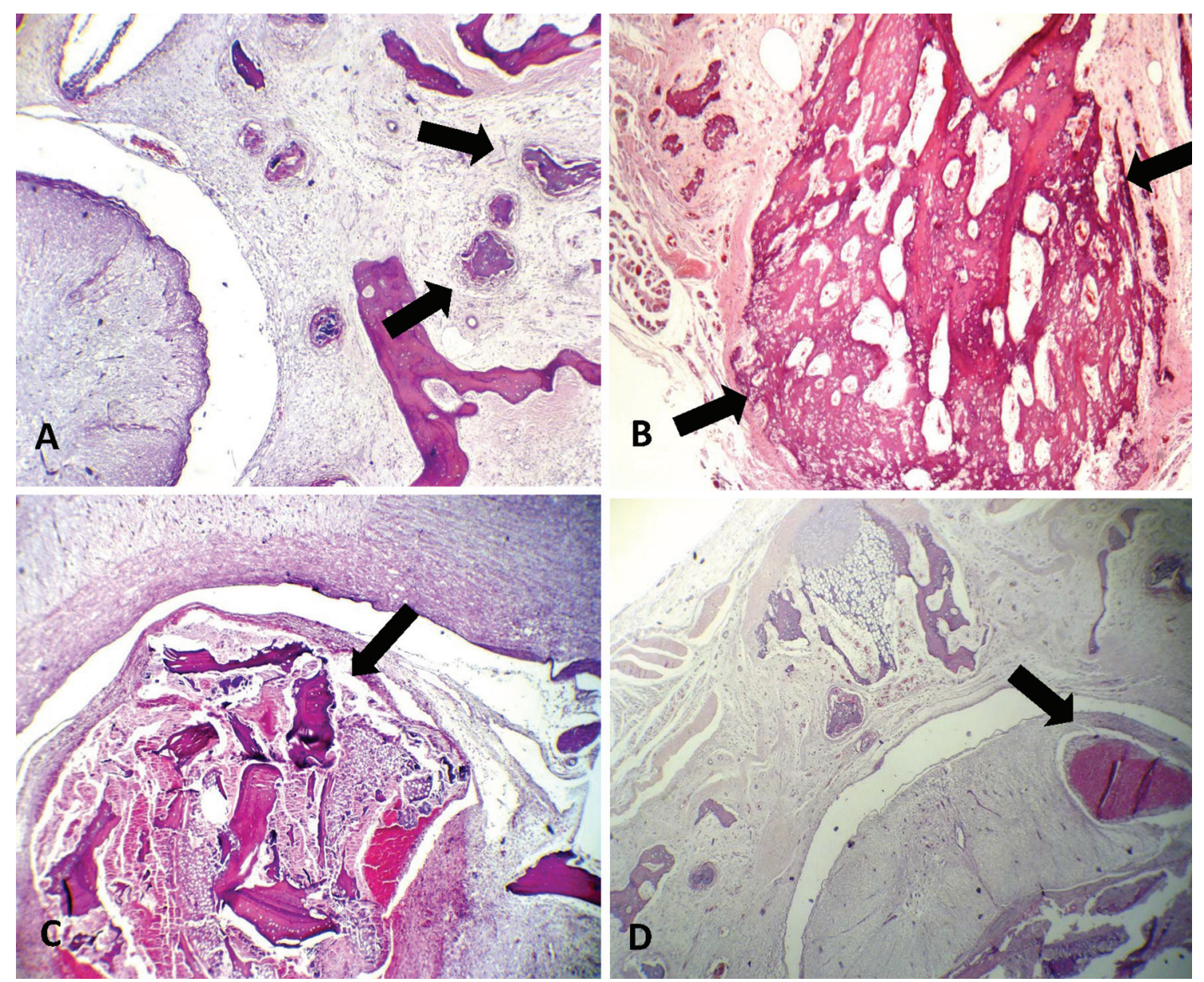

Fig.3. (A) Granulomas multifocais (setas) com material basofílico ao centro. HE, obj.4x. (B) Extensa área de regeneração óssea, lacunas ósseas com presença de osteócitos e osteoide moderadamente basofílico, bordos pouco homogêneos (seta), e grande quantidade de osteoblastos periféricos. HE, obj.10x. (C) Corpo vertebral fraturado com deslocamento para a cavidade vertebral (seta) e compressão da medula espinhal. HE, obj.10x. (D) Área focal bem delimitada de necrose do tecido nervoso da medula espinhal (seta), associado à fratura do corpo vertebral e compressão da medula espinhal. HE, obj.40x. Comparar a conformação anatômica da medula espinhal entre as Figuras 3A (normal) e 3C e 3D (comprimidas).

árias. Salmonella sp. é o agente oportunista mais frequente dentre as bactérias citadas, e suas lesões associadas com a IBD costumam ser estomatite, pneumonia e osteomielite (Schilliger et al. 2011), assim como o quadro desse relato.

A estomatite encontrada no animal é um problema comum em cobras e lagartos de cativeiro, e mesmo quando se trata de um problema isolado, o principal agente responsável é Salmonella sp. (Jacobson 2007a, Bastos 2012). Isso acontece porque répteis de cativeiro são pré-dispostos a lesões na cavidade oral por dois motivos: por desenvolverem uma microbiota oral diferenciada, trocando a maioria das bactérias Gram positivas pelas Gram negativas, o que facilita a infecção por diversos patógenos (Jacobson 2007a, Bastos 2012) já que a microflora oral estabelece uma importante barreira protetora que ocupa os receptores das células e secreta substâncias que inibem o crescimento exacerbado das Enterobacteriacea (Hirsh 1990b). E segundo, porque lesões orais em serpentes são facilitadas por atrito contra as estruturas do recinto, mordedura de camundongos dos quais se alimentam, temperaturas impróprias, má nutrição e pelo hábito das cobras de utilizarem a língua como órgão sensorial, expondo-a próxima ao solo e, se contaminando com as fezes do recinto (Jacobson 2007a). A lesão na cavidade oral não foi disponível para análise microbiológica ou histopatológica e por isso não foi possível confirmar se a lesão era uma estomatite por salmonelose.

Estomatite por Salmonella sp. é a principal razão pela qual serpentes de cativeiro desenvolvem pneumonia, devido à aspiração de tecidos necróticos agregados às colônias da lesão oral (Jacobson 2007a), porém, a ausência de alterações nesse animal que caracterizariam a pneumonia aspirativa (Santos \& Guedes 2014) leva a acreditar que a pneumonia não foi por essa razão. Salmonella sp. também pode causar pneumonia secundária a septicemia, nesse caso por via hematógena (Hirsh 1990a, 1990b, Quinn et al. 2000, Cullen \& Brown 2013) o que levaria à inflamação primeiramente no interstício (Santos \& Guedes 2014), como encontrado no caso. Por outro lado, a presença de diversos corpúsculos de inclusão direciona nosso diagnóstico para pneumonia em consequência da IBD. Chang \& Jacobson (2010) relatam que a doença do corpúsculo de inclusão pode estar associada a infiltrado inflamatório.

A invasão da Salmonella sp. pelo intestino não gera, necessariamente, uma lesão no local. Após a entrada para 

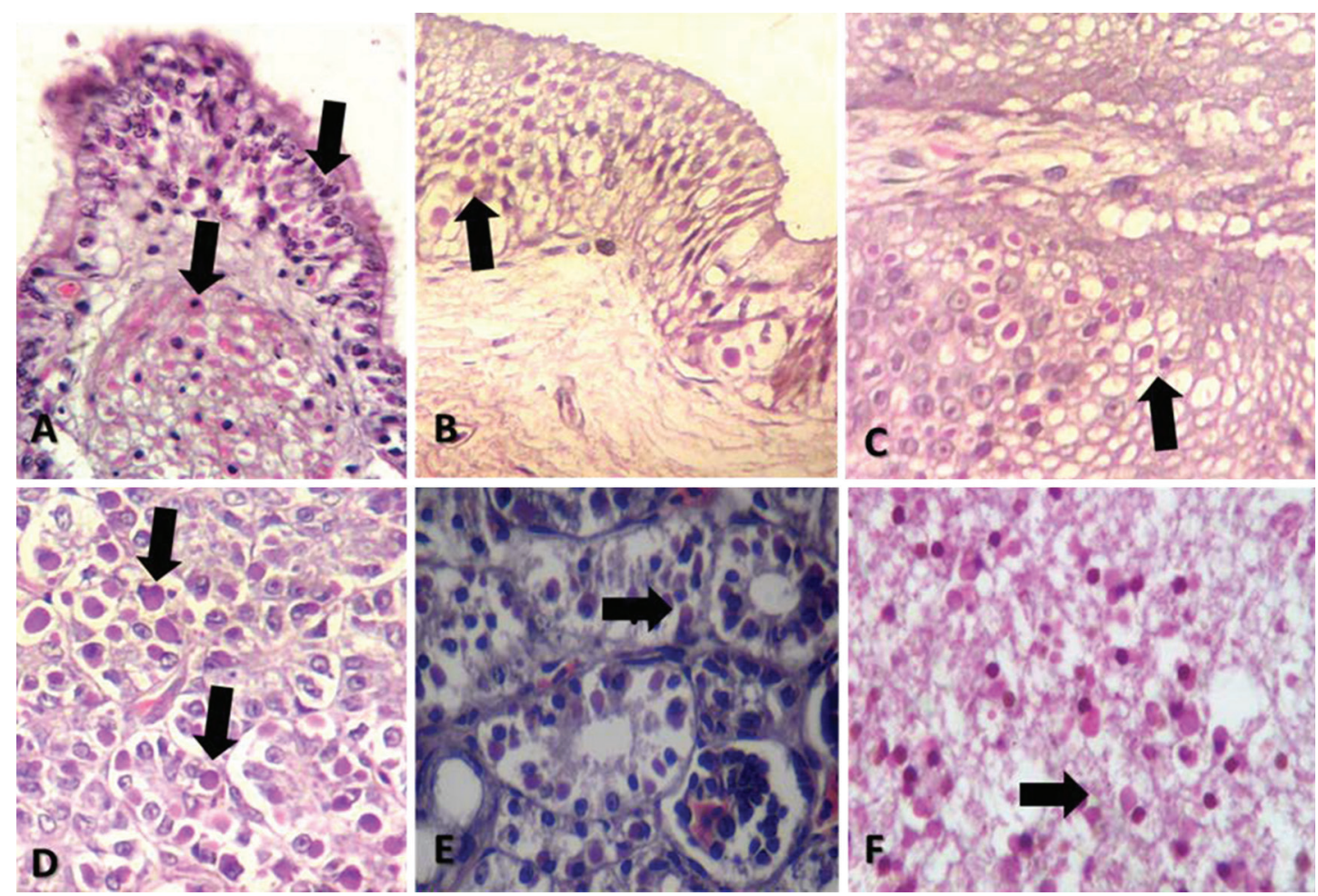

Fig.4. Diversas estruturas eosinofílicas a anfofílicas (setas) disseminadas predominantemente no citoplasma das células epiteliais, de (A) brônquio, (B) vesícula biliar, (C) intestino grosso, (D) pâncreas, (E) túbulos renais e (F) substância branca do encéfalo; associadas às Inclusões nota-se degeneração vacuolar das células. HE, obj.40x.

dentro dos macrófagos, as bactérias chegam à circulação portossistêmica, o que forma uma lesão característica conhecida como fígado paratifoide em mamíferos (Cullen \& Brown 2013, Gelberg 2013, Zachary 2013, Guedes et al. 2014). A Boa constrictor constrictor tinha necrose hepática aleatória multifocal moderada, com infiltrado inflamatório linfohistiocítico, que é semelhante à lesão hepática caracterizada pela salmonelose, porém branda (Cullen \& Brown 2013, Gelberg 2013, Zachary 2013, Guedes et al. 2014). Dessa forma, é possível que a disseminação da Salmonella sp. no organismo tenha sido a fecal-oral (Hirsh 1990b, Quinn et al. 2000, Jacobson 2007a, Bastos 2012).

Foi possível isolar a bactéria nas lesões das vértebras, e não do fígado ou coágulo cardíaco, possivelmente porque no tecido ósseo, os capilares são estreitos e com grande quantidade de fenestrações, o que facilita a penetração e disseminação do agente no local, mas, a circulação no tecido ósseo é lenta e há uma relativa deficiência fagocitária tecidual que contribui para a implantação da infecção. Uma vez aderidas às proteínas, elas se camuflam, o que dificulta as ações defensivas do sistema imune e a ação de antibióticos (Thompson 2007).

Ainda, segundo Thompson (2007), a manifestação clínica da osteomielite pode se manifestar meses após o insulto inicial, quando há deformidades ósseas visíveis, dor, restrição de movimentos e fratura patológica no local. Grandes focos de necrose ou áreas que perderam o suprimento sanguíneo devido à infecção local podem ter persistido, formando nichos bacterianos que dificultam a reparação do processo, o que pode explicar a característica crônico-ativa das lesões ósseas na serpente examinada.
Outra lesão crônica evidente encontrada é a formação de necrose extensa margeada por atividade osteoclástica levando à fratura patológica, que ocorre devido à permanência da bactéria na lesão, que mantém o estímulo inflamatório e a secreção de substâncias que geram osteoclasia. A fratura patológica pode facilitar a disseminação da Salmonella sp. para a cavidade espinhal, e contaminar outras vertebras. Como algumas vértebras mostravam lesões recentes, pode ter acontecido uma inflamação por exsudação do material necrótico, com ou sem a presença da Salmonella sp. Da mesma forma se explica o comprometimento da medula espinhal que tinha um infiltrado semelhante ao das vértebras e uma extensa área de necrose focal, que pode piorar a restrição de movimentos e gerar sinais neurológicos através da disseminação pelo sistema nervoso (Thompson 2007, Bastos 2012). Além disso, a medula espinhal foi comprimida levando a uma necrose neuronal nos fragmentos acometidos.

A lesão no encéfalo se caracterizava por acentuada quantidade de corpúsculos de inclusão disseminados, associado à ausência de inflamação, áreas de necrose ou qualquer indicação de reação tecidual secundária às infecções bacterianas; por isso, infere-se que a lesão medular não ascendeu para o encéfalo e que os achados clínicos e histopatológicos referentes ao cérebro eram consequência da IBD. Outra evidência que suporta essa afirmação é que os principais sinais clínicos da IBD são neurológicos (Chang \& Jacobson 2010, Stenglein et al. 2012, Hetzel et al. 2013), como expressados pela jiboia, que tinha convulsões e opistotóno.

Segundo Schumacher et al. (1994) sinais clínicos da 
IBD podem ser agudos ou demorar diversos meses para se manifestarem, além disso, jiboias são consideradas mais resistentes à afecção (Chang \& Jacobson 2010, Stenglein et al. 2012), por isso, apesar da doença do corpúsculo de inclusão facilitar a salmonelose, serpentes podem ter osteomielite por Salmonella sp. independentemente da IBD. Posto isso, não se pode afirmar qual enfermidade apareceu antes, já que não foi realizado nenhum diagnóstico prévio para IBD.

Com a recente identificação do agente da IBD, várias pesquisas têm sido realizadas. Até o momento sabe-se que é um vírus que consegue se replicar em uma temperatura ideal de $30^{\circ} \mathrm{C}$, e não sobrevive sobre temperaturas superiores à $37^{\circ} \mathrm{C}$ (Hepojoki et al. 2015). Essa descoberta explicou o porquê a IBD é uma doença de pet's e animais de cativeiro, uma vez que o recinto desses animais tem uma temperatura controlada superior ao ambiente natural, alcançando a faixa térmica ideal para a replicação viral (Hepojoki et al. 2015). No Brasil, em algumas regiões, a temperatura é alta mesmo nos meses de inverno, e é possível que, diferentemente da Europa e dos Estados Unidos, nos trópicos essa enfermidade seja importante também para animais de vida livre.

Ainda que o número de doenças víricas em répteis seja relativamente alto, pouco se sabe sobre as enfermidades de origem viral nessas espécies. Desses agentes, muitos podem não expressar importância clínica e são apenas achados histopatológicos de exames post morten (Schumacher 2005). Independente se o animal expressa a doença clinicamente, ele pode ser portador e transmitir para terceiros (Chang \& Jacobson 2010, Stenglein et al. 2012). Por isso, quando se refere à IBD, a eutanásia em serpentes acometidas é recomendada (Chang \& Jacobson 2010), pelo potencial risco de infectar populações inteiras, devido à alta morbidade e mortalidade (Schumacher 2006), e principalmente por não se conhecer o suficiente a doença, já que in vitro o agente da IBD foi capaz de infectar células de mamíferos (Hepojoki et al. 2015). Ainda são necessárias pesquisas que esclareçam se esta afecção é um problema para a saúde pública (Stenglein et al. 2012).

\section{CONCLUSÕES}

Conclui-se que a Boa constrictor constrictor desenvolveu doença do corpúsculo de inclusão e espondilite por salmonelose. Não foi possível estabelecer qual afecção se iniciou primeiro, para elucidar se a IBD levou a pré-disposição à salmonelose, ou se foram duas enfermidades independentes.

A IBD é uma doença de importância mundial, provavelmente negligenciada no Brasil pela carência de relatos e estudos epidemiológicos no país. Ressalta-se que há necessidade de maiores estudos sobre a IBD para conhecimento de seus hospedeiros, patogenia e formas de controle.

\section{REFERÊNCIAS}

Bastos H.M. 2012. Salmonella associated with snakes (Suborder Serpentes), p.81-98. In: Annous B.A. \& Gurtler J.B. (Eds), Salmonella, Distribution, Adaptation, Control, Measures and Molecular Technologies. Intech Open Science, São Paulo.
Bodewes R., Kik M.J.L., Stalin Raj V., Schapendonk C.M.E., Haagmans B.L., Smits S.L. \& Osterhaus A.D.M.E. 2013. Detection of novel divergent arenaviruses in boid snakes with inclusion body disease in The Netherlands. J. Gen. Virol. 94:1206-1210.

Chang L.W., Fu A., Wozniak E., Chow M., Duke D.G., Green L., Kelley K., Hernandez J.A. \& Jacobson E.R. 2013. Immunohistochemical detection of a unique protein within cells of snakes having inclusion body disease, a World-wide disease in members of the families Boidae and Pythonidae. PLoS ONE 8(12):e82916. doi:10.1371/journal.pone.0082916.

Chang L.W. \& Jacobson E.R. 2010. Inclusion body disease, a worldwide infectious disease of boid snakes: a review. J. Exotic Pet Medicine 19(3):216-225.

Cullen J.M. \& Brown D.L. 2013. Sistema hepatobiliar e pâncreas exócrino, p.407-460. In: Zachary J.F. \& McGavin M.D. (Eds), Bases da Patologia em Veterinária. 5a ed., Mosby, Rio de Janeiro.

Gelberg H.B. 2013. Sistema Alimentar, Peritônio, Omento, Mesentério e Cavidade Peritoneal, p.324-406. In: Zachary J.F. \& McGavin M.D. (Eds), Bases da patologia em Veterinária. 5a ed., Mosby, Rio de Janeiro.

Guedes R.M.C., Brown C.C. \& Sequeira J.L. 2014. Sistema digestório, p.87176. In: Santos R.L. \& Alessi A.C. (Eds), Patologia Veterinária. Roca, São Paulo.

Hepojoki J., Kipar A., Korzyukov Y., Saakyi L.B., Vapalahti O. \& Hetzel U. 2015. Replication of boid inclusion body disease-associated arenaviruses is temperature sensitive in both boid and mammalian cells. J. Virol. 89(2):1119-1128. DOI: 10.1128/JVI.03119-14.

Hetzel U., Sirone T., Laurinmäki P., Liljeroos L., Patjas A., Henttonen H., Vaheri A., Artelt A., Kipar A., Butcher S.J., Vapalahti O. \& Hepojoki J. 2013. Isolation, identification, and characterization of novel arenaviruses, the etiological of boid inclusion body disease. J. ASM org JVI, EDENext 116.

Hirsh D.C. 1990a. The alimentary canal as a microbial habitat, p.93-97. In: Biberstein E.L. \& Zee Y.C. (Eds), Rewiew of Veterinary Microbiology. Blackwell Scientific Publication, USA.

Hirsh D.C. 1990b. Family Enterobacteriacea, p.209-236. In: Biberstein E.L. \& Zee Y.C. (Eds), Rewiew of Veterinary Microbiology. Blackwell Scientific Publication, USA.

Jacobson E.R. 2007a. Bacterial Disease of Reptiles, p.461-526. In: Jacobson E.R. (Ed.), Infectious Disease and Pathology of Reptiles: color atlas and text. CRC Press, Florida.

Quinn P.J., Carter M.E., Markey B. \& Carter G.R. 2000. Enterobacteriacea, p.98-102. In: Quinn P.J., Carter M.E., Markey B. \& Carter G.R. (Eds), Clinical Veterinary Microbiology. Mosby, London.

Santos R.L. \& Guedes R.M.C. 2014. Sistema respiratório, p.1-50. In: Santos R.L. \& Alessi A.C. (Eds), Patologia Veterinária. Roca, São Paulo.

Schilliger L., Selleri P. \& Frye F.L. 2011. Lymphoblastic lymphoma and leukemic blood profile in a red-tail boa (Boa constrictor constrictor) with concurrent inclusion body disease. J. Vet. Diagn. Invest. 23:159-162.

Schumacher J. 2005. Viral diseases, p.147-151. In: Mader D.R. (Ed.), Reptile Medicine and Surgery. W.B. Saunders, California.

Schumacher J. 2006. Selected Infectious Disease of Wild Reptiles and Amphibians. J. Exotic Pet Med. 15(1):18-24.

Schumacher J., Jacobson E.R., Homer B.L. \& Gaskin J.M. 1994. Inclusion body disease in boid snakes. J. Zoo Wildl. Med. 25(4): 511-524.

Stenglein M.D., Sanders C., Kistler A.L., Ruby J.G., Franco J.Y., Reavill D.R., Dunker F. \& Derisi J.L. 2012. Identification, Characterization, and In Vitro Culture of Highly Divergent Arenaviruses from Boa Constrictors and Annulated Tree Boas: candidate etiological agents for snake inclusion body disease. mBio 3(4). doi:10.1128/mBio.00180-12.

Thompson K. 2007. Bones and joints, p.1-184. In: Maxie M.G. (Ed.), Jubb, Kennedy and Palmer's Pathology of Domestic Animals. 5th ed. W.B. Saunders, Mosby.

Turchetti A.P., Tinoco H.P., Malta M.C.C., Costa M.E.L.T., Pessanha A.T., Soave S.A., Paixão T.A. \& Santos R.L. 2013. Inclusion body disease in a Corallus hortulanus. Braz. J. Vet. Pathol .6(1):15-18.

Zachary J.F. 2013. Mecanismos das infecções microbianas, p.147-241. In: Zachary J.F. \& McGavin M.D. (Eds), Bases da Patologia em Veterinária. 5a ed. Mosby, Rio de Janeiro. 